Motrivivência Ano XXI, No 32/33, P. 71-88 Jun-Dez./2009

\title{
O LEGADO EDUCATIVO DOS MEGAEVENTOS ESPORTIVOS
}

Katia Rubio'

\section{Resumo Abstract}

Quando no final do século XIX foi celebrada a primeira edição dos Jogos Olímpicos da Era Moderna

e a cidade de Atenas acolheu a competição pouco se esperava de

um evento que reunia algumas centenas de pessoas que praticavam esporte como atividade de tempo livre e sem nenhuma outra finalidade senão a competição em si mesma. Ao longo do século XX os Jogos Olímpicos se transformaram em um dos principais eventos culturais do planeta e sua organização demanda envolvimento direto do poder público e da iniciativa privada. De um sonho multicultural e multiétnico a um dos maiores negócios do planeta os Jogos Olímpicos, a maior realização do Comitê Olímpico Internacional,
When in the late nineteenth century was celebrated for the first Olympic Games of the Modern Age and the city of Athens hosted the competition little was expected of an event that brought together hundreds of people who practice sports as leisure-time activity and for no other purpose than the competition itself. Throughout the twentieth century the Olympics have become a major cultural events of the planet and your organization demands the direct involvement of public and private initiative. From a multicultural and multiethnic dream to a one of the biggest business on the planet the Olympics, the greatest achievement of the International 
tornaram-se uma fonte inesgotável de reprodução de valores culturais e de projeção da dinâmica social. Este artigo propõe-se a discutir os valores olímpicos inicialmente apregoados, identificados em princípio como valores éticos universais, e a proposta de educação olímpica como forma de resgate desses valores e de reflexão sobre os rumos que o movimento como um todo toma em um mundo marcado pelas diferenças não apenas culturais, mas também econômicas e sociais.

Palavras-chave: Jogos Olímpicos; Valores olímpicos; Educação olímpica.

\section{Os Jogos Olímpicos como mega- eventos dos séculos XX e XXI}

O Movimento Olímpico contemporâneo tem como principal ideólogo Pierre de Freddy, conhecido pelo título nobiliárquico de Barão de Coubertin. Educador, pensador e historiador, empenhou-se na reorganização dos Jogos. Sua preocupação fundamental era valorizar a competição leal e sadia, o culto ao corpo e à atividade física.

Após conhecer as escolas inglesas, onde o esporte moderno foi organizado e se desenvolveu, Pierre de Coubertin visitou diversos países para saber como o esporte era praticado e como ele se estruturava. Depois de vários anos per-
Olympic Committee, became an inexhaustible source of reproduction of cultural values and projection of social dynamics. This article proposes to discuss the Olympic values initially touted as identified in principle as universal ethical values, and the proposed Olympic education as a way to rescue these values and reflection on the direction the movement as a whole takes on a world marked by differences not only cultural but also economic and social.

Keywords: Olympic Games; Olympic values; Olympic education.

cebeu que em diferentes lugares do mundo, mesmo sem falar o mesmo idioma, as pessoas eram capazes de jogar e competir. Ou seja, o esporte era uma linguagem universal. Coubertin começou a freqüentar a École Supérieure des Sciences Politiques na qual teve contato com a pessoa e a obra de Hipólito Taine e com um núcleo anglófilo que buscava compreender a dinâmica cultural inglesa onde se originava o modelo de esporte moderno. De acordo com Tavares (2003) duas características da sociedade inglesa interessavam a Coubertin e iriam influenciar sobremaneira sua obra e suas ações: uma delas era o 'espírito de associação' da sociedade inglesa corporificado nas associações privadas de patronato; o segundo 
Ano XXI, n 32/33, junho e dezembro/2009

foi o sistema educacional inglês, onde se educava para a vida numa sociedade.

Embora Coubertin encontrasse em Taine o eco necessário para a reflexão sobre um modelo pedagógico foi em Frédéric Le Play que a reforma social por meio de uma pedagogia esportiva encontrou sua principal referência (Mangan, 1986). Coubertin começou a se preocupar em desenvolver um modelo de reforma social por meio da educação e do esporte em uma perspectiva internacionalista depois de obter pouco sucesso com programas de caráter educacional em seu país, a França. MacAloon (1984) aponta que durante os idos de 1880 visitou inúmeras escolas inglesas, uma verdadeira peregrinação, em busca de referência para seu projeto esportivo-pedagógico, deslocando, entretanto esse micro sistema - a educação - do macro sistema - a sociedade - no qual ele estava inserido e situado. Não satisfeito com isso, em 1889, partiu para os Estados Unidos para conhecer de perto o modelo educacional americano. Nessa oportunidade Coubertin mostrou-se surpreso com os 'sentimentos democráticos do catolicismo americano' que separava igreja do Estado e tolerava a liberdade de culto, fato menos comum na Inglaterra. Talvez essa questão tenha Ihe chamado tanta atenção em virtude da resistência que os países de cultura puritana ofereciam à idéia dos jogos Olímpicos, relacionando-os com uma festa pagã, extinta pelo imperador Teodósio, um católico fervoroso, a pedido do bispo de Milão, San Ambrosio, no ano de 394 (Guttman, 1992; 1978).

Foi, sobretudo, o renascimento do interesse pelos estudos clássicos, fazendo reviver na intelectualidade de então a fascinação que a cultura helênica exercia sobre a cultura européia, além das descobertas de sítios arqueológicos que permitiam desvendar acontecimentos relacionados aos Jogos Olímpicos da Antiguidade, que levou Pierre de Coubertin a tomar para si a tarefa de organizar uma instituição de caráter internacional com a finalidade de cuidar daquilo que seria uma atividade capaz de transformar a sociedade daquele momento: o esporte. Tavares (2003) aponta que o estabelecimento do Movimento Olímpico nos idos de 1894 coincide com a criação e proliferação de um amplo espectro de organizações de cunho internacionalista, cujo principal objetivo era a promoção da paz. Isso porque, embora durante o século XIX tivesse ocorrido um grande desenvolvimento das ciências humanas e da produção de idéias, os conflitos ainda eram resolvidos 
de forma brutal por meio da guerra. As organizações internacionalistas buscavam a resolução de conflitos, tanto de ordem interna como externa, pelo uso da razão e das leis, e não pelas armas. Dentro dessa lógica a competição esportiva era uma forma racionalizada de conflito, sem o uso da violência.

O projeto de restauração dos Jogos Olímpicos como na Grécia Helênica veio a público em 25 de novembro de 1892 quando da ocasião do $5^{\circ}$ aniversário da União das Sociedades Francesas de Esportes Atléticos, que teve como paraninfo o Barão de Coubertin. Naquela ocasião ele manifestaria seu desejo e intenções com relação os Jogos: É preciso internacionalizar o esporte. É necessário organizar novos Jogos Olímpicos (López, 1992:21). A tarefa audaciosa de promover uma competição esportiva de âmbito internacional, espelhada nos Jogos Olímpicos gregos, com caráter educativo e permanente, demandava a criação de uma instituição que desse o suporte humano e material para a realização de tal empreitada. E assim, em junho de 1894, na Sorbonne, em Paris, teve início o congresso esportivo-cultural, no qual Coubertin apresentou a proposta de recriação dos Jogos Olímpicos e da criação do Comitê Olímpico Internacional (COI). Inicialmente o Barão intentava realizar a primeira edição dos Jogos Olímpicos na capital francesa em 1900, como parte das comemorações da virada do século que ocorreria em seis anos. Entretanto, diferentemente do que havia sugerido o proponente, a competição foi antecipada para o ano de 1896, para Atenas, como uma deferência aos criadores dos jogos originais (Rubio, 2006). A missão e intenção do COI era organizar os Jogos Olímpicos bem como a normatizar as modalidades disputadas, muitas delas recémcriadas e sem um corpo de regras universalizadas. A idéia inicial, e que posteriormente foi perpetuada, era da celebração de uma competição de caráter internacional, com realização quadrienal, cujos participantes estariam vinculados a representações nacionais.

De acordo com Tavares (1999.a) os Jogos Olímpicos eram para Coubertin a institucionalização de uma concepção de práticas de atividades físicas que transformava o esporte em um empreendimento educativo, moral e social, destinado a produzir reflexos no plano dos indivíduos, das sociedades e das nações. A definição de Olimpismo contida nos Princípios Fundamentais da Carta Olímpica (2001) é pouco precisa ou, como afirma DaCosta (1999), uma filosofia em processo durante o tempo de vida de Coubertin - o que tem levado 
Ano XXI, n 32/33, junho e dezembro/2009

estudiosos do tema a discussões extensas e inconclusivas (Grupe, 1992; Sagrave, 1988). Vale ressaltar que o termo Olimpismo refere-se ao conjunto de valores pedagógicos e filosóficos do Movimento Olímpico, e não aos aspectos formais e/ou burocráticos que sustentam a instituição e o fenômeno olímpico.

As modernas Olimpíadas, ou seja, o período em que ocorrem as edições dos Jogos Olímpicos, dividem-se em Jogos de inverno e de verão, ocorrem de quatro em quatro anos, como na Antigüidade, alternando-se a cada dois anos entre os Jogos de Verão e os de Inverno. Diferentemente da dificuldade para definição da sede ocorrida nas edições iniciais, na atualidade, a realização das competições é disputada por grandes metrópoles dos cinco continentes, em um processo que demanda alguns anos.

Para os gregos, os Jogos representavam um momento de trégua nas guerras e conflitos de qualquer ordem para que competidores e espectadores pudessem chegar a Olímpia. Ao longo desse um século de competições os Jogos Olímpicos da Era Moderna já sofreram interrupção por causa das duas Grandes Guerras e boicotes promovidos por Estados Unidos e União Soviética na década de 1980, indicando que o Movimento Olímpico não está alheio às questões sociais e políticas do mundo contemporâneo como desejava Pierre de Coubertin.

\section{A educação olímpica como legado dos Jogos Olímpicos}

Desde que Pierre de Coubertin deu início ao Movimento Olímpico no final do século XIX, ele não desejava apenas criar uma competição esportiva. Alguns princípios éticos, pedagógicos e morais norteavam essa prática, que hoje representam a face pública do Olimpismo. Dentre esses valores encontram-se o estímulo à participação da mulher no esporte, a proteção ao atleta, o desenvolvimento sustentável, o respeito à Trégua Olímpica, a promoção da cultura e da educação olímpica e a organização dos Jogos Olímpicos.

Esses valores funcionam como um Código de Conduta do Movimento Olímpico e buscam nortear as atitudes e ações de todos os envolvidos nas atividades olímpicas, sejam elas competitivas, administrativas ou voluntárias. Para tanto busca combinar esporte, educação e cultura a partir da harmonia entre o corpo e a mente, da excelência em si mesmo, da integridade nas ações, do respeito mútuo e da alegria no esforço (Rubio, 2009). Cabe ressaltar que o termo Olimpismo refere-se ao conjunto de valores pedagógicos e filosóficos do Movimento Olímpico, e não apenas os 
Jogos Olímpicos.

Conforme aponta Futada (2007) enquanto as dúvidas e críticas quanto a eficácia e a validade de um modelo educacional pautado na formação de valores estão presentes nas discussões atuais sobre educação, a perspectiva idealizada de ser humano como produto e produtor de uma conduta ética e justa já contempla outras questões como o real sentido de justiça e ética e as relações de poder. Muito embora já se tenha pensado sobre condições mínimas necessárias para que todos tenham acesso e garantia de qualidade de vida, conforme a Declaração Universal dos Direitos Humanos, sabe-se dos conceitos distintos e, talvez ainda mais importante, compreendidos sobre questões como justiça, ética e valores para diferentes grupos sociais. Diante disso apresenta as principais questões a serem debatidas em um projeto de educação para os valores olímpicos a partir das idéias de Muller (2004).

\section{A busca da perfeição e do de- senvolvimento harmonioso}

O conceito de desenvolvimento integral pode sugerir inúmeras dúvidas quanto a seus objetivos e amplitude. As críticas com relação a essa visão de ser humano e de educação de Coubertin devem ser compreendidas dentro de uma perspectiva histórica, que, como já mencionado, tinha suas influências significativas para que o mosaico do Olimpismo fosse construído dessa forma. Essa abordagem defende que deve haver uma busca por uma formação do indivíduo na sua totalidade, sem fragmentação de domínios biológicos, psicológicos e sociais, entendendo o esporte e a atividade física como elementos fundamentais para essa realização. Dentro dessa perspectiva Coubertin já defendia ao final no século XIX a existência da Educação Física no ambiente escolar como disciplina obrigatória. Sua abordagem, no entanto, não afirmava o esporte como especialização, mas como a possibilidade de intervenção educacional, dialogando com outras manifestações como a arte e a música.

A idéia de perfeição humana compreende que os Jogos Olímpicos são a maior demonstração de façanhas, auto-superação e de estabelecimento de recordes possíveis dentro do universo esportivo se comparados a outras competições, e que esse caráter de transcendência dos Jogos está presente no próprio conceito de Olimpismo onde a busca de desenvolvimento é uma constante. Esta ideologia pode ter sido em grande parte influenciada pelos valores presentes no modelo 
Ano XXI, n 32/33, junho e dezembro/2009

da agonística grega. O princípio da agonística é caracterizado, segundo Durantez (1977), como toda atividade em que exista confronto ou mútua oposição entre os protagonistas que dela participem, apresentada em forma de disputa pacífica ou amistosa, própria e característica da prática esportiva, mantendo respeito ao competidor que associava o próprio desempenho às virtudes do adversário, valorizando o respeito e dignidade da competição.

A interdependência desses conceitos significa uma necessidade recíproca do enfrentamento do obstáculo, pois é somente dessa forma que os próprios limites e capacidades podem ser superados. O competidor compreende ser parte de um ciclo transformador e, portanto, comporta-se com a citada ética esportiva, participando de forma justa, respeitando o adversário, as regras de competição e o valor onipresente do embate.

Essa perspectiva é cabível não somente ao atleta em situações competitivas de alta performance, mas a qualquer indivíduo que se engaja na prática de um esporte ou atividade física e busca melhoras em seu desempenho, novamente sempre pautadas nos princípios de honestidade e justiça. Novamente buscando um paralelo com as influências do modelo de educação da Paidéia Grega, esse entendimento da agonística como manifestação presente nas situações esportivas está diretamente vinculado ao conceito de areté.

Segundo Brandão (1999) areté é a expressão daquilo que se poderia definir como excelência ou superioridade que se revelam particularmente no campo de batalha e nas assembléias, por meio da arte da palavra. A areté, no entanto, é uma outorga de Zeus: é diminuída, quando se cai na escravatura, ou é severamente castigada, quando o herói comete uma hýbris, uma violência, um excesso, ultrapassando sua medida, o métron, desejando igualar-se aos deuses. Conseqüência lógica da areté é a timé, a honra que se presta ao valor do herói, que se constitui na mais alta compensação do guerreiro. É a dike, a justiça, que não permite crescer a hýbris ou o descomedimento.

A disputa individual na superação de limites e aperfeiçoamento físico e espiritual era realizada tanto nos campos de batalha quanto nas celebrações mítico-religiosas em homenagem aos deuses mitológicos (Jogos Olímpicos, Jogos Fúnebres, etc.). Nessas ocasiões eram realizadas diversas provas esportivas e culturais e, dentro desse contexto, surgia no participante a busca pela areté não por doutrina imposta, mas pela incessante busca de valores e princípios vivos adquiridos na 
convivência com aqueles que já se mostravam diferenciados (Munguia, 1992 ; Rubio, 2001).

\section{A ética na atividade esportiva}

Sob essa idéia espera-se desenvolver um dos conceitos basilares do Olimpismo, conhecido como fair play. O fair-play presume uma formação ética e moral daquele que pratica e se relaciona com os demais integrantes de uma competição, e que esta pessoa não fará uso de outros meios que não a própria capacidade para superar os oponentes. Nessas condições não há espaço para formas ilícitas que objetivem a vitória, suborno ou uso de substâncias que aumentem o desempenho.

De acordo com Turini (2002) o fair play é entendido como a ética do esporte moderno cujo propósito é orientar a conduta do competidor na prática esportiva. Dentre os valores culturais ingleses com os quais Pierre de Coubertin teve contato, o fair play foi sem dúvida aquele que mais influência exerceu sobre sua concepção de Olimpismo. A gênese do fair play está fincada no cavalheirismo, base do comportamento que definia o ideal de homem na sociedade inglesa do século XIX. A transposição para o âmbito esportivo dessa atitude social foi idealizada e empregada desde o surgimento do Movimento Olímpico contemporâneo, afirmando a relação de projeção que há entre sociedade-cultura e movimento olímpico-esporte. Embora hegemônica, a cultura inglesa não era universal, portanto, é de se esperar que o fair play também não representasse uma unanimidade.

Tavares (1999.b) endossa essa afirmação apontando que as implicações do fair play enquanto um conjunto de valores normativos dos comportamentos no ambiente da competição reflete a formulação de um ambiente cultural específico. Sendo assim, ainda que o Olimpismo, e o fair play em particular, tenham adquirido alguma expressão hipoteticamente universal, é altamente recomendável que se examine o significado atual do fair play a partir de um cenário cultural multidimensional. (p. 178)

Em outro trabalho Tavares (2003) cita o filósofo alemão Gunter Gebauer para discutir o paradoxo inerente ao esporte que associa a 'liberdade de excesso' (altius, citius, fortius) e o cavalheirismo (fair play) por serem dificilmente compatíveis diante das codificações éticas e princípios morais em um campo onde o que prevalece são as ações práticas. Há condições objetivas que levam a essa conclusão.

Mesmo quando as regras não mudam ou mudam pouco, o 
Ano XXI, n 32/33, junho e dezembro/2009

desenvolvimento da preparação física, o aumento da 'seriedade' da competição e toda a carga de mudanças competitivas trazida pela crescente lógica profissional do esporte, determinam uma dinâmica e um sentido novos que fazem um mesmo esporte se tornar um jogo bastante diferente. A busca pela vantagem, por sua chance, é o que determina a perspectiva interna que um atleta tem na situação competitiva, a maneira como organiza ações e a quantidade e a qualidade dos recursos que ele mobiliza para atingir seus objetivos. (p.102)

Diante do universalismo sugerido e desejado pelo Olimpismo seria de se esperar que o multiculturalismo fosse contemplado em respeito aos diversos atores sociais que protagonizam os Jogos Olímpicos, a principal manifestação do Movimento Olímpico. Entretanto, assim como o ideal de amadorismo, o fair play foi concebido a partir de uma perspectiva cultural dominante, e como decorrência natural eurocêntrica (ou anglocêntrica), em um momento em que a estrutura e organização olímpica restringiam-se a um grupo restrito de pessoas que tinham a si próprios como referência para a criação de regras.

Os estudos sobre o fairplay têm recebido a atenção de estudiosos do Olimpismo preocupados com as transformações que vêm ocorrendo nas regras e conduta dos praticantes das diversas modalidades esportivas, bem como do avanço dos estudos culturais (Lenk, 1986; Loland, 1995; Mangan, 1996; Marivoet, 1998; Tavares, 1999.a). Isso porque o próprio Movimento Olímpico criou padrões, normas e orientações que norteiam e influenciam a prática e o entendimento do esporte, tanto por parte de quem o pratica como de quem o assiste.

A compreensão e aplicação do fair play envolvem elementos emocionais e cognitivos que levaram Lenk (1986) a postular duas manifestações possíveis:

- o fair-play formal que está relacionado diretamente ao cumprimento de regras e regulamentos escritos e formalizados que o participante da competição deve cumprir, em princípio, sendo considerado como uma 'norma obrigação' (must norm). É o comportamento normatizado, caracterizado como um comportamento objetivo.

- o fair-play não formal - relaciona-se ao comportamento pessoal e aos valores morais do atleta e daqueles envolvidos com o mundo esportivo. Não 
está limitado por regras escritas e é legitimado culturalmente. A ausência de uma regulamentação oficial confere a ele um caráter subjetivo. É o comportamento efetivo influenciado pelos estados emocionais e motivacionais.

Apesar de caracterizado por uma abordagem normativa e conservadora do comportamento atlético, o fair-play serviu durante longo período como orientação para os protagonistas do espetáculo esportivo, ainda que não fosse seguido durante todo o tempo.

\section{Multiculturalismo, interna- cionalismo e alteridade}

Ao longo do século XX o esporte constituiu-se como um espaço privilegiado para a construção de identidades e de desenvolvimento da alteridade, não apenas no Brasil como na maioria dos países Ocidentais. Concebo a alteridade como a consideração e o respeito às diferenças entre os indivíduos (Rubio \& Daolio, 1997).

A amizade e a fraternidade são consideradas o coração do Movimento Olímpico. Isso porque levam à convivência social, ao entendimento e a amizade, à compreensão independente da nacionalidade. Por isso o Olimpismo se apresenta como uma linguagem de reconhecimento universal, o que favorece a busca da paz e o reconhecimento de igualdade entre os povos. Quando Pierre de Coubetin desenvolveu a idéia do Olimpismo acreditava que o Movimento Olímpico se justificava como promotor do entendimento intercultural e que o esporte era uma linguagem universal a todos os povos e que, portanto, todas as pessoas do mundo poderiam praticá-lo independente do lugar onde estivessem. Naquele momento histórico pouco se estudava a respeito das diferenças entre os grupos sociais, principalmente porque os países europeus dominavam grande parte do mundo e impunham sua cultura como melhor e mais correta.

Diante de seu valor socializante, o esporte favorece a cooperação e a amizade internacional, permitindo aos povos respeitaremse mutuamente. Entende-se a partir dessa perspectiva a necessidade do adversário para que a competição se dê de forma justa e honesta e para que o indivíduo se descubra a si mesmo.

Müller (2004) atribui ao Movimento Olímpico, ao Olimpismo e principalmente ao forte exemplo dos Jogos Olímpicos, um potencial estímulo tanto à compreensão internacional através do esporte, como à prática de relações de respeito e tolerância interpessoal 
Ano XXI, n 32/33, junho e dezembro/2009

entre os indivíduos envolvidos na prática esportiva. Independentemente do nível em que seja feita a análise, espera-se que o esporte pautado por ideais filosóficos e comportamentais traga consigo toda uma gama de exemplos e geração de oportunidades para a melhora dessas competências.

Para Futada (2007) essa tomada de atitude, que pode ser compreendida inclusive como uma transcendência da questão do conviver, está diretamente relacionada à construção do indivíduo na sua subjetividade e, no caso do internacionalismo, na construção da identidade cultural de determinado grupo. Essa organização prévia da identidade pessoal e social seria condição para que os envolvidos nessa dinâmica educacional identificassem o que de fato lhes confere sua subjetividade e só então passassem a reconhecer o que lhes é diferente, numa demonstração de alteridade.

Nesse conceito Coubertin já aponta para a distinção entre patriotismo e nacionalismo. O Barão defenderia o espírito de sociedade presente no Movimento Olímpico estimulando o amor à pátria. Por outro lado entendia que o pensamento nacionalista deveria ser execrado uma vez que junto dele poderiam estar presentes atitudes xenofóbicas e preconceituosas. Os Jogos Olímpicos seriam um momento de con- gregação, onde as disputas de poder ou as atitudes e intencionalidades de diferenciação negativa não deveriam existir. Muito embora essa fosse uma preocupação inicial de Coubertin na construção do Olimpismo, estudos mostram que as dinâmicas do jogo de poderes e formas de comparação sempre estiveram presentes no Movimento Olímpico.

A formação do caráter dentro desses preceitos se dá pelo autoconhecimento, pelo autocontrole e pela auto-realização. Isso porque o esporte permite a manifestação da liberdade, da espontaneidade, da fantasia criadora e o desejo de identificação com as condições reais da vida. E por meio dessa ação educadora se dá a formação do caráter. Ao conjunto de diferentes manifestações culturais e a convivência com muitas formas de cultura é dado o nome de multiculturalismo, cujo foco central é o respeito e a valorização das diferenças, o que significa a negação do racismo ou de qualquer outra forma de preconceito ou discriminação. No esporte isso representa o respeito às diversas manifestações corporais, sejam elas olímpicas ou não.

Coubertin entendia que o Olimpismo, principalmente por meio dos Jogos Olímpicos, poderia estimular a compreensão internacional, como o desempenho de relações de respeito e tolerância 
interpessoal entre os indivíduos envolvidos na prática esportiva. Acreditava que o esporte pautado por esses ideais filosóficos poderia fornecer exemplos e gerar oportunidades para o exercício da cordialidade entre pessoas de diferentes países, a inclusão e a paz. Essa atitude de respeito à diferença está diretamente relacionada à construção do indivíduo na sua subjetividade, ou seja, naquilo que há de mais particular e específico da sua existência. Considerando que essa subjetividade é construída na relação com o grupo social ao qual o indivíduo pertence, estaria assim formada as bases da identidade cultural em diferentes países.

No século XIX o esporte era uma prática de identidade cultural na Inglaterra. Isso porque muitas das modalidades esportivas que conhecemos hoje foram originadas dos jogos e das brincadeiras realizadas pelas crianças e jovens nas festas populares. Mais tarde, para que os estudantes das escolas inglesas pudessem praticar as modalidades e competir entre si foi preciso sistematizar um conjunto de regras, o que depois facilitou a mesma prática em outros países do mundo. Isso permitiu a idéia dos Jogos Olímpicos, uma vez que atletas de vários países podiam competir sob o mesmo sistema de regras.
Da mesma forma que a regra facilita a competição entre atletas de diferentes países ela não permite que se manifestem outras formas de praticar a modalidade esportiva. Essa é a marca do esporte olímpico: ser praticado da mesma forma, com as mesmas regras e os mesmos equipamentos em qualquer país participante da instituição que regule a modalidade.

\section{Emancipação, ambientalismo e autonomia}

A dinâmica que subjaz ao esporte e suas manifestações deveria ser construída sobre um forte sentimento de responsabilidade social. Para isso seria necessário atentar sobre as questões de igualdade de direitos na prática do esporte, com o devido respeito às diferenças individuais. Portanto, questões relacionadas a temas como os direitos humanos, gênero, diferenças sociais e etnia no esporte, devem ser não ignoradas, mas explicitadas e trabaIhadas valendo-se do próprio esporte como ferramenta de desmistificação e transformação de alguns pressupostos, eliminando preconceitos e estereótipos que trabalhem no sentido oposto desta proposta.

Pode-se observar que o esporte olímpico não é a única prática de cultura corporal de movimento. 
Ano XXI, n 32/33, junho e dezembro/2009

Há ainda muitas modalidades esportivas como forma de identidade cultural, como é o caso dos Jogos Indígenas, no Brasil ou a pelota basca na Espanha. A atividade corporal é uma maneira de um grupo social ou uma nação apresentar sua história e suas tradições construídas a partir da vivência de várias gerações.

A idéia de que a geografia esportiva não coincide com a geografia política resultou em um movimento internacional denominado Países Desportivos. Isso porque hoje em dia há países com território delimitado, apesar de não ser reconhecido como Estados Nacionais. É o caso de Barcelona e País Basco, na Espanha; País de Gales, Irlanda do Norte e Escócia, no Reino Unido; Porto Rico, Alaska e Havaí, nos Estados Unidos da América; Taiwan, Hong Kong e Macau, na China e ainda Palestina, Kosovo, Flandres, Ilhas Norfolk e Quebec. Esses territórios são delimitados geograficamente por produções culturais e sociais que Ihes conferem identidades próprias. Entendem a atividade física e o esporte como atividades livres que devem ser promovidas e organizadas por instituições que atuam de acordo com valores culturais e sociais mais significativos de cada território e de cada momento histórico. E assim promovem as várias manifestações esportivas do local, sejam elas olímpicas ou não.
O Movimento Olímpico demonstrou ao longo dos anos grande preocupação com as questões relacionadas ao patriotismo e ao nacionalismo. Desde Coubertin se entendia que o pensamento patriótico não deveria ser exaltado porque isso poderia gerar atitudes xenofóbicas (preconceito contra o diferente, o estrangeiro) e preconceituosas. Os Jogos Olímpicos deveriam ser um momento de confraternização, onde as disputas pelo poder ou as atitudes de discriminação não deveriam existir.

Mais recentemente a questão ambiental ganhou espaço na agenda olímpica. O desenvolvimento sustentável parte da noção de que a preservação a longo prazo dos recursos naturais e ambientais não pode ser feita sem que haja, simultaneamente, um desenvolvimento econômico, social e político que beneficie em particular os mais desfavorecidos. Durante a Conferência das Nações Unidas sobre Meio Ambiente e Desenvolvimento (CNUMAD), denominada Rio 92, as nações do mundo inteiro assumiram o compromisso de fazer com que o desenvolvimento econômico se processe de maneira a proteger o meio ambiente e os recursos não renováveis do planeta. A noção de desenvolvimento sustentável foi acatada como o conceito central que deve ser 
respeitado na implementação dos planos de desenvolvimento para o século XXI.

A aplicação do conceito de desenvolvimento sustentável é responsabilidade do conjunto de pessoas ou instituições de importância reconhecida no desenvolvimento e na proteção ambiental. Entendendo que essa questão está em conformidade com a filosofia do Olimpismo, com a Carta Olímpica, particularmente em seus parágrafos terceiro e sexto dos Princípios Fundamentais, e com o fato da sua universalidade, o Movimento Olímpico entende que the cabe a responsabilidade especial de participar da aplicação do conceito de desenvolvimento sustentável. A agenda 21 foi o documento produzido nesse evento que busca implementar o conceito de desenvolvimento sustentável

O Movimento Olímpico que tem por objetivo contribuir para a construção de um mundo de paz e melhor, compartilha a análise levada a cabo pela Rio 92 e insere sua ação na perspectiva do desenvolvimento sustentável. Pelo fato de o Movimento Olímpico ter, graças sobretudo à universalidade do esporte, a capacidade de participar ativamente da implantação de mediadas em defesa do desenvolvimento sustentável, o Comitê Olímpico Internacional decidiu dotar o Movimento Olímpico de sua própria Agenda 21.
A Agenda 21 é um plano de ação para ser adotado global, nacional e localmente, por governos ou pela sociedade civil, em todas as áreas em que a ação humana interfere no meio ambiente. Esta é a tentativa mais abrangente já realizada no sentido de orientar para um novo padrão de desenvolvimento para o século XXI, onde se busca uma relação entre a sustentabilidade ambiental, social e econômica (DaCosta, 1997). A Agenda 21 do Movimento Olímpico tem por objetivo incentivar os membros desse Movimento a participar ativamente do desenvolvimento sustentável de nosso planeta. Além disso, propõe às instâncias dirigentes campos de integração do desenvolvimento sustentável as suas políticas. Às pessoas, indica formas de ação que as converterão em agentes desse desenvolvimento sustentável graças à maneira com que vivem o esporte e também ao seu modo de ser.

Diante do desafio de implementar as ações propostas para o desenvolvimento sustentável o Movimento Olímpico pensou em um programa de ação que deve permitir a melhoria das condições sócio-econômicas, a preservação do meio ambiente e dos recursos naturais e o fortalecimento do papel de seus membros na implantação dessas ações. Esses programas de ação abrangem a melhoria das 
Ano XXI, n 32/33, junho e dezembro/2009

condições sócio-econômicas, a conservação e gestão dos recursos para um desenvolvimento sustentável e o fortalecimento do papel dos principais grupos envolvidos.

A luta contra a exclusão está presente nesse documento. Entende o Movimento Olímpico a prática do esporte tem um papel essencial na luta contra a pobreza. Por isso entende que as instituições esportivas devem apoiar prioritariamente o desenvolvimento da prática desportiva nas zonas de menos recursos financeiros. Por isso as organizações esportivas devem ajudar a incentivar as instituições públicas relacionadas com o esporte a promover a prática desportiva pelos grupos humanos que, por razões econômicos e de gênero, raça ou casta, dela se acham excluídos. Tais instituições devem favorecer o desenvolvimento prioritário de infra-estrutura e equipamentos esportivos nas zonas mais carentes ou marginalizadas.

Há vários anos o Movimento Olímpico considera o meio ambiente como o terceiro pilar do Olimpismo, depois do esporte e da cultura. Para tanto, desenvolveu uma política de defesa do meio ambiente expressa no "Pacto da Terra", bem como as ações de colaboração com a Rio 92, a organização de Jogos Olímpicos "verdes" e a realização de conferências mundiais e regionais sobre o esporte e o meio ambiente. Isso porque a realização de uma edição de Jogos Olímpicos altera profundamente a vida da cidade sede que passa por uma grande reformulação, alterando o cotidiano de seus moradores. Por isso, quando da construção ou remodelação de instalações ou do planejamento de eventos desportivo de envergadura, seus responsáveis cuidarão de realizar um estudo prévio do impacto ambiental que permita assegurar o respeito ao meio ambiente cultural, social e natural.

É por causa dessa preocupação que as atividades e instalações esportivas bem como as competições deverão ser realizadas com a preocupação de preservar os lugares, as paisagens, os bens culturais e o conjunto das riquezas naturais de onde elas se realizam. A escolha dos locais para realizá-las também deverá ser feita com o cuidado de minimizar o impacto sobre o meio ambiente produzido pelas infra-estruturas que lhes serão incorporadas, como vias de circulação, redes de comunicações e de fornecimento de eletricidade, construção de alojamentos, abastecimento de água e de alimentos, lançamento e tratamento do lixo.

Para assegurar o sucesso do desenvolvimento sustentável no Movimento Olímpico é indispensável que o conjunto dos grupos que 
constituem esse Movimento sejam agentes ativos na construção de um mundo melhor. A prática democrática requer o acesso às fontes de informação. Sob essa ótica, o Movimento Olímpico pode prestar uma contribuição concreta no fortalecimento dos papéis sociais das mulheres e dos jovens, bem como das comunidades indígenas que representam uma parcela significativa da população humana e o fato de que elas são com freqüência objeto de exclusão social.

\section{Considerações finais}

Superado o romantismo inicial que moveu e motivou a criação do Movimento Olímpico, assistimos na atualidade a uma complexa trama de interesses a mover ideais e ações no campo olímpico. De um sonho multicultural e multiétnico a um dos maiores negócios do planeta os Jogos Olímpicos, a maior realização do Comitê Olímpico Internacional, tornaram-se uma fonte inesgotável de reprodução de valores culturais e de projeção da dinâmica social.

O esporte contemporâneo, bem como o Movimento Olímpico, deve ser entendido dentro da dinâmica social dos séculos XX e XXI. Isso porque tem-se visto uma ruptura da estrutura do esporte atual com os valores propostos originalmente, o que impede que o Olimpismo de então seja entendido e praticado na atualidade da mesma maneira. Transformado em produto de consumo o esporte, de maneira genérica, e o olímpico, mais especificamente, tiveram que se adequar para satisfazer às exigências de um mercado consumidor ávido por limites e movimento, premido ainda pelo veículo máximo de exposição desses feitos: os diversos meios de comunicação de massa. Não se pode negar que a televisão transformou a audiência do esporte em todo o mundo, e na medida que começou a perder a capacidade de subsistir enquanto espetáculo ao vivo, tornou-se dependente de patrocínios gerados pela abrangência das transmissões televisivas. Essa situação provocou o incremento do profissionalismo no esporte, tanto no que se refere à possessão do espetáculo pela televisão como em relação àquele que protagoniza o espetáculo, o atleta.

O distanciamento gradativo dos valores inicialmente apregoados tem levado à promoção de ações identificadas com valores éticos universais e, portanto, de ampla aceitação, como foi a proposta olímpica inicial. Discutir a função da educação olímpica surge em um momento de crise desses valores e de reflexão sobre os rumos que o movimento como um todo toma 
Ano XXI, n 32/33, junho e dezembro/2009

em um mundo marcado pelas diferenças não apenas culturais, mas também econômicas e sociais.

Resgatar a dimensão ética e moral das práticas culturais e corporais de movimento nos mobiliza na construção de caminhos que correm para além das práticas educativas formais. A proposta que se fez ao longo desse texto vem no sentido de apontar direções sobre os temas caros aos valores olímpicos, sem, contudo ditar as formas como fazêlo. Isso porque em outros momentos históricos os conteúdos foram universalizados e circunscritos a práticas hegemônicas, desprezando as especificidades das culturas locais. Sendo assim, ficam aqui apontados os temas gerais que norteiam essa proposta e um convite a resgatar de seu grupo social os elementos a serem desenvolvidos e interpretados dentro desse conjunto de valores que se dizem olímpicos.

\section{REFERÊNCIAS}

BRANDÃO, J. Mitologia grega. V. I Petrópolis: Vozes, 1999.

DaCOSTA, L. P. (ed.) Sport and Enviroment. An international overview. Porto: FCDEF, 1997.

CARTA OLÍMPICA. Lausanne: Comitê Olímpico Internacional, 2001.
DURANTEZ, C. Las Olimpíadas Gregas. Pamplona: Comitê Olímpico Espanhol, 1977.

FUTADA, F. Educação Olímpica: Conceito e Modelos. In.: K. Rubio (org.) Educação olímpica e responsabilidade social. São Paulo: Casa do Psicólogo, 2007. GRUPE, O. The sport culture and the sportization of culture: identity, legitimacy, sense and nonsense of modern sports as a cultural phenomenon. In: F. Landry et alii (eds) Sport... the third millennium. Quebec: Les Presses de l'Université Laval, 1992.

GUTTMANN, A. History of the modern games. Illinois: University of Illinois, 1992.

GUTTMANN, A. From ritual to record. New York: Columbia University Press, 1978.

LENK, H. Toward a social philosophy of the Olympics: values, aims and reality of the modern Olympic Movement. In: P. J. Graham \& H. Ueberhorst (eds) The modern Olympics. West Point: Leisure Press, 1976.

LOLAND, S. Fair play. Historical anachronism or a topical ideal? International Seminar on Philosophical Issues in Sport and Physical Education. 17-19 Março, 1995.

LÓPEZ, A. A. La aventura olímpica. Madrid: Campamones, 1992. 
MacALOON, J. J. This great symbol. Chicago: The University of Chicago Press, 1984.

MANGAN, J. A. The games ethic and imperialism. New York/ Middlesex: Viking Penguin, 1986.

MARIVOET, S. Aspectos sociológicos do desporto. Lisboa: Livros Horizonte, 1998.

MULLER, N. Olympic Education: University lecture on the Olympics [online article]. Barcelona: Centre d'Estudies Olimpics (UAB). International Chair in Olympism (IOC - UAB), 2004. <http: // olympicstudies.uab.es/lectures/ web/pdf/muller.pdf>

MUNGUIA, S.S. Los Juegos Olimpicos, Educacioón, deporte, mitologia y fiestas em la antigua Grecia. Madrid: Anaya, 1992.

RUBIO, K. Esporte, educação e valores olímpicos. São Paulo: Casa do Psicólogo, 2009.

RUBIO, K. Medalhistas Olímpicos

Brasileiros: memórias, história e imaginário. São Paulo: Casa do Psicólogo, 2006.

RUBIO, K. O atleta e o mito do herói. São Paulo: Casa do Psicólogo, 2001.

RUBIO, K.; DAOLIO, J. A incorporação da alteridade como caminho para a construção da cidadania. Anais do X Congresso Brasileiro de Ciências do Esporte, 1997, p. 109 a 113.
SAGRAVE, J. O. Toward a definition of Olympism. In: (J. O. SAGRAVE \& D. B. CHU, eds.) The Olympic Games in transition. Champaign: Human Kinetics, 1988.

TAVARES, O. Esporte, movimento olímpico e democracia: o atleta como mediador. Tese de doutorado. Programa de Pósgraduação em Educação Física. Universidade Gama Filho. Rio de Janeiro, 2003.

TAVARES, O. A. Referenciais teóricos para o conceito de Olimpismo. In: O. Tavares \&

L. P. DaCosta (eds) Estudos Olímpicos. Rio de Janeiro: Editora Gama Filho, 1999.a.

TAVARES, O. Algumas reflexões para uma rediscussão do fair-play. In: O. Tavares \& L. P. DaCosta (eds) Estudos Olímpicos. Rio de Janeiro: Editora Gama Filho, 1999. b.

TURINI, M. A prática do fair play no contexto da atualidade. In.: (M. Turini; L. P. DaCosta, orgs) Coletânea de textos em Estudos Olímpicos. Rio de Janeiro: Universidade Gama Filho, 2002.

Recebido: Junho/2010 Aprovado: Agosto/2010 